\title{
Development of Health Care e-Services in the European Union
}

\author{
Ana Stanković, Hrvoje Stančić \\ Department of Information and Communication Sciences \\ Faculty of Humanities and Social Sciences \\ Ivana Lučića 3, Zagreb \\ ana.stankov3@gmail.com, hstancic@ffzg.hr
}

\section{Summary}

Development and implementation of e-services has become a common practice of state and public administrations in the developed countries around the world since the usage of information and communication technologies has enabled a faster processing of user applications and more efficient functioning of the service. This paper analyses the level of development of e-services in health care systems of eight European countries, both in terms of safety and reliability from the perspective of end users, i.e. citizens. Furthermore, the concept of trust in eservices based on the availability of information on the Internet on applied technological solutions, storage and data protection and their availability is considered. Implementation of services like e-health records and e-prescriptions requires a well-developed strategy and a very transparent way of their functioning because of the sensitive nature of health data. For this study official websites of the services were searched through, as were other sources on the Internet. The research results indicate a lack of certain key information, especially those related to data storage, their protection and long-term preservation.

Keywords: e-services, e-health record, e-prescription, health, trust

\section{Introduction}

Nowadays ICT has entered all aspects of human activity and even more people prefer using the Internet for dealing with their everyday transactions. Therefore, the state and public administrations of countries around the world have recognised the need to make their services available through the Internet. As one of the most commonly used e-services have proven to be those related to health care. These e-services have positively affected the business optimization in health care sector (Menachemi and Collum, 2011) although the benefits are to be visible several years after the implementation due to the high implementation costs and the time needed for the users to start using the e-services (Saluse et al., 2010). The most commonly implemented health care e-services are e-health records and e-prescriptions. Considering the fact that health-related data are very sensitive, many questions about the security and confidentiality of these e- 
services need to be answered (Smith and Eloff, 1999). For example, who has access to such data? How are users' data protected from unwanted access? How are users guaranteed that their data are protected from unauthorised access? Answers to these questions are relevant particularly nowadays when medical data are at risk of misuse by outsiders as well as insiders (Anderson, 1996). The aim of this research was to get answers to these and other similar questions and to gain insight to the way in which different state and public administrations solved some of the problems related to the security and confidentiality of health care e-services.

\section{E-services}

One can distinguish two main different categories of e-services developed by the government: G2C (Government-to-Citizen) and G2B (Government-to-Business) services. When searching for the definition of e-services one can come across many formulations from different sources, but regardless of the scope and depth of different definitions of e-services, they all point out that e-services:

a) are available through the Internet,

b) provide a particular service (partially or completely), and

c) optimise operations (Piccinelli and Stammers, 2001).

Table 1. Stages of development of an e-service

\begin{tabular}{|c|l|l|}
\hline Stage & Action & Description \\
\hline 0 & No information & $\begin{array}{l}\text { Information about the service is not available on-line or the } \\
\text { service provider does not have a website. }\end{array}$ \\
\hline 1 & Information & Only information about the service is available on-line. \\
\hline 2 & One-way interaction & $\begin{array}{l}\text { There are forms in electronic format that are available for } \\
\text { downloading. Blank forms can be printed out. }\end{array}$ \\
\hline 3 & Two-way interaction & $\begin{array}{l}\text { Forms can be filled out and signed after authentication. By } \\
\text { completing forms one runs a specific service. }\end{array}$ \\
\hline 5 & Transaction & $\begin{array}{l}\text { The complete service is available on-line: completing } \\
\text { forms, authentication, payment and delivery of receipts or } \\
\text { other forms of complete service. }\end{array}$ \\
\hline & $\begin{array}{l}\text { Services are repetitive and automatically executed. Users } \\
\text { are notified automatically about the execution of the } \\
\text { service. }\end{array}$ \\
\hline
\end{tabular}

Since not all of the e-services are developed and implemented at the same level, different stage models are used in order to classify them according to their technical specifications and degree of service they provide to the citizens. One of them was presented at the Lisbon Summit in the year 2000. In this model (Table 1 ), which was used in this research as well, there are 5 (or 6) stages of development (Digitizing Public Services in Europe, 2010). 


\section{Health care e-services}

Health care e-services that are the most commonly implemented at the moment are e-health records and e-prescriptions. E-health record is a set of medical information about an individual in the electronic form, usually containing personal and demographic data, patient medical history, laboratory results and other information related to the health of the individual. Although e-health record is considered to be one of the key decision making tools regarding the patient's health, it is necessary to enable the patient to preserve the privacy of certain data sets (Barrows and Clayton, 1996). It is necessary to provide certain restriction measures to a patient which he/she will be able to use in order to prevent doctors from having access to some data sets of their e-health record.

E-prescription refers to prescribing medications using ICT by the authorized health professionals. The implementation of e-prescription service optimises the entire process of purchasing drugs (Cornford et al., 2014), it prevents the inability to read the recipe due to sloppy handwriting and it makes it easier to track which medications are used most often, speeds up the process, and has ecological side because it saves paper.

The study presented in this paper is part of a larger research conducted within the InterPARES Trust project. InterPARES (International Research into the Preservation of Authentic Records in Electronic Systems) Trust "is a multi-national, interdisciplinary research project exploring issues concerning digital records and data entrusted to the Internet. Its goal is to generate theoretical and methodological frameworks to develop local, national and international policies, procedures, regulations, standards and legislation, in order to ensure public trust grounded on evidence of good governance, a strong digital economy, and a persistent digital memory."1

\section{An overview of the implemented health care e-services in the chosen EU countries}

\section{Research methodology and limitations}

The research was carried out between 15 January and 15 July 2014. The sample covered eight EU countries: Belgium, Croatia, Denmark, Estonia, Germany, Lithuania, Sweden, and the United Kingdom. Prior to the selection of these 8 countries an environmental scan was carried out. Then, the countries that have implemented their e-services on a higher level or have shown the intention to do so have been selected for the in-depth research. A questionnaire consisting of 52 questions divided into six categories was conducted. The six categories are:
A. Basic service information,
B. Users,
C. Business optimisation,

\footnotetext{
${ }^{1}$ InterPARES Trust project, http://interparestrust.org/ (07.01.2015.)
} 
D. Technological solutions,

E. Storage and long-term content availability,

F. System operation transparency.

The data collection was done between 15 February and 15 May 2014. The data were collected by the researchers. They searched for information that was openly available on the Internet. Sources of information were primarily the official websites of e-services or other sites that offered information about their implementation. After the collection of information was finished, the data was analysed quantitatively and qualitatively. Limitations of the study are reflected in the fact that in some cases the information was not available because of the language barrier, because of technical maintenance of the website, or other technical issues. There is a possibility that certain information was available on the Internet but could be reached only after logging in to the system, and therefore was out of reach for this study.

\section{Research results}

The data were collected for each of the 52 questions divided into six categories (A-F) for each of the eight surveyed EU countries. Then, the collected data were analysed at the level of each country and each e-service, and finally for all of the researched countries and for both e-services together. Next, the questions within each of the six main categories will be mentioned first, and then the aggregated results of the research will be given and commented.

\section{A. Basic service information}

The questions in this category were aimed to gather information on the service URL, service category, category/type of institution authorized for the e-service, start of service development/implementation, level of informatization, connection with any other governmental services, comparison of official and actual development of the e-service, limitations to the service's work schedule, short description of the service etc.

Developing and implementing e-services is a complicated and lengthy process so even though the interest for implementing health care e-services has occurred back in the 1990s most of the researched services were implemented by governments in the period from 2003 to 2009. In most countries e-health records are at the 3rd level of informatization and e-prescriptions are usually between level 3 and 4 since they meet all of the criteria related to the 3rd level and most of those related to the 4th level. E-health records and e-prescriptions are usually interconnected and offer round-the-clock service.

\section{B. Users}

This category consisted of the following questions: Is using the service mandatory for a certain category of users? If yes, which category of users is it mandatory for? Are there different groups of users? How many users are there per user 
group? What is the percentage of users who use the service electronically? Which age groups are prevalent in using the service? Is the service adapted for users with disabilities? Are there users' satisfaction information?

Answers from this set of questions were found for Estonia and Denmark, both of which point out high percentage of users of e-health record (in Estonia 47\% of citizens and $95 \%$ of doctors use e-health record and in Denmark almost $100 \%$ of doctors use it). When it comes to e-prescriptions, the percentage of users who use the service electronically in all of the researched countries is quite high, $75 \%$ and higher. The percentage of satisfied users in all of the researched countries for both services is quite high and it ranges from $80 \%$ to $95 \%$. On the other hand, web sites of services in most of the researched countries have not shown the clear intention to adopt the service to the people with special needs. The only exception is Sweden where they have adapted the service for users with disabilities.

\section{Business optimisation}

The following questions on business optimisation were considered: Are there positive financial indicators for e-service (for the institution responsible for service and for users)? Has there been a decrease in time required to process user applications? How did the service affect the organisation of work processes in the responsible organization in terms of the required number of workers? What are the plans for upgrading and expanding the service in the future?

Business optimisation is visible on several levels. Estonia had the first financial gains from implementing e-health record in 2010 (2 years after implementing the service). In Croatia it is estimated that the implementation of e-prescription service should result with savings of 15 million HRK per year. In the United Kingdom it is assumed that implementation of e-prescriptions will result with total savings of 179 million pounds a year at the level of the entire health care system $^{2}$. In Denmark implementation of e-health record greatly enhanced the efficiency of the health care system with average savings of 50 minutes per day through reduced paperwork and faster communication. In Estonia the use of eprescriptions contributed to savings of approximately 30 minutes per day. In conclusion, the use of e-prescription is helping to save time on several levels:

a) it ensures doctors the possibility to repeat the prescribed medicine thus reducing the number of patient visits or calls,

b) pharmacists can prepare the medicine in advance thus reducing waiting time,

c) there is less possibility of errors due to illegible handwriting, and

d) there is no risk of losing the prescription since the data is stored in the central database.

\footnotetext{
${ }^{2}$ Electronic prescription service, NHS England, http://systems.hscic.gov.uk/eps/library/ nhsecomms.pdf (20.6.2014.)
} 
Also, plans for upgrading and expanding the system can be categorized into several groups:

1. technical upgrades (e.g. plans for developing a national eID system, the introduction of smart cards etc.)

2. improving data management, and

3. educating health care professionals.

\section{Technological solutions}

The following questions regarded technological solutions were included in the survey: What type of authentication is used? Is the communication between the server and client station encrypted (SSL, some other protocol)? Does the service use eID? If yes, which one (list all if more than one eID exists)? Does the electronic signature use digital certificates? If yes, which format of electronic signatures is used? In what way does the user fill in and send data? Do the users send attachments with the filled in data? If yes, in what way? Do the users have predetermined types of document formats while sending out data? If yes, which ones? Is the service implemented through open-source or commercial technologies? Which technologies are being used? What type of application is used on the client side? Through which channel(s) is the service available? Is the service hosted within the responsible institution? If the responsible institution is hosting the service, does it have the required certificates? If the service or any of its parts is hosted outside the responsible institution, does it use the Cloud? Is the Cloud/Data centre located within the same country?

All countries that have implemented these e-services offer their users the possibility to access them by using any device with Internet connection and a browser. Most of them use eID cards for authentication when using e-health records (Graph 1) and smart cards when using e-prescriptions (Graph 2). We assumed that doctors usually fill in a web form in order to send data and that they use some of the standardized formats (.doc, .tiff, .pdf, etc.) when sending certain attachments (x-rays, results of different tests, etc.). Information on using digital certificates is available for Denmark and Estonia where they use the XAdES (XML Advanced Electronic Signature) format of electronic signatures. Belgium, Denmark and the United Kingdom provided information on conforming to ISO 27001 and ISO 9001 standards. However, there is no information available weather any of the services use cloud solutions which could be either due to the fact that the cloud solutions still raise a lot of security issues so they are still not implemented within this kind of e-services or the information on the usage is not available. 


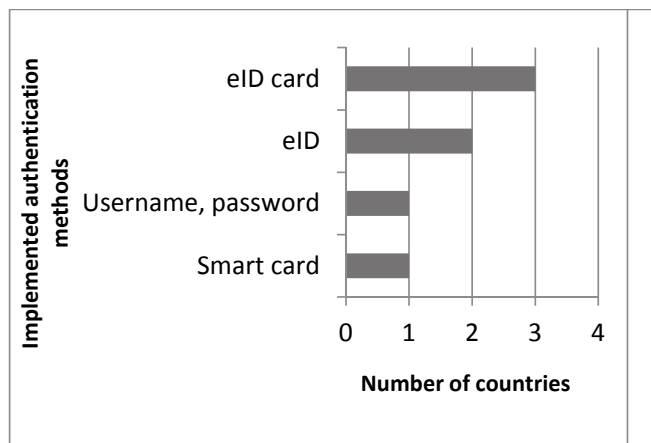

Graph 1. Type of authentication (e-health records)

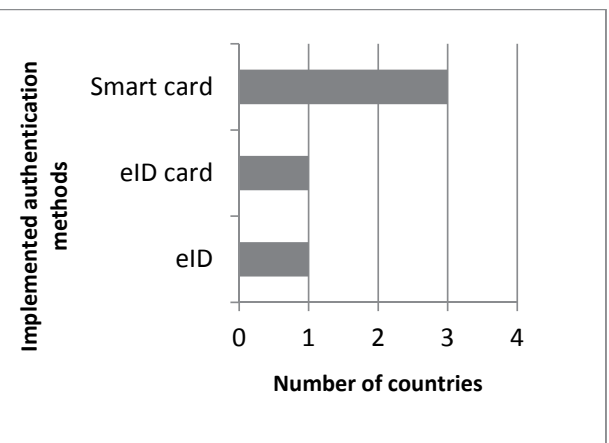

Graph 2. Type of authentication (e-prescriptions)

\section{E. Storage and long-term content availability}

The questions investigating storage and long-term content availability were: What is the retention period for the data in the system? Is the retention period defined by a law/regulation or some other act? If yes, which one? Are the data deleted after the retention period expires? What is the preferred long-term preservation format(s)? Does the service use a method of materialization of data (conversion from digital to analogue format, e.g. printing, microfilming etc.)? Does the service comply with any of the long-term preservation standards? If yes, which one? Does the service offer use of an electronic archive as an additional service? Are there electronic document safe services? Are the data received through the service stored within the responsible institution's information system? Does the responsible institution possess the required certificates that guarantee security of the stored data? If the data are at least partially stored outside the responsible institution, does it use Data Cloud? Is the Cloud/Data center located within the same country as the responsible institution?

Information on storage and long-term content availability was found for Sweden, the United Kingdom and Croatia. In Sweden data from the patients' health records are kept permanently, while in the United Kingdom the retention period is 30 years. In Croatia the data should be kept for 70 years from their creation or 100 years from a person's birth. In the United Kingdom the retention period for e-prescriptions is 2 years and after the retention period expires the data are deleted in a controlled environment. In most of the surveyed countries, a centralized national database is used for data storing except for Estonia where the national database is not centralized (although it may seem so). Rather they use the $\mathrm{X}$-Road platform for data exchange which allows data storing from different sources (which may use different systems). In all of the researched countries, the data from the e-prescription services are stored in a centralized database. 


\section{F. System operation transparency}

The system operation transparency was investigated through questions: Is there a defined service use policy? Are there any proclaimed technological measures guaranteeing the users that their data are only used for the defined purpose? Are the employees required to sign a non-disclosure agreement? Can users access and view their data through the service? Can users correct or update any of their data within the service? If yes, can the request for correction be sent electronically? Can users monitor status of their application?

In almost all of the surveyed countries users are able to access and view their data. In Estonia doctors have the possibility to prohibit patients from accessing their e-health records if they estimate it would have a certain negative impact to their health/mental condition. On the other hand, a patient can also prohibit doctors' access to his/hers e-health record. This allows users to control their personal data, but the problem may appear when same rules of prohibition apply in emergencies when a patient may not be in condition to allow a doctor to access his/hers e-health record. In Sweden patients may prohibit doctor's access to certain data, except in emergencies. In Belgium citizens can update data in their e-health records by adding information about any potential complications that have occurred while using certain drugs, information about their health condition etc. On the other hand, in Estonia citizens can update only their demographic data.

It is necessary to provide users with the ability to monitor the state of their ehealth record by providing information about who and for what reason accessed their data and/or made changes. In most of the researched countries (Belgium, Denmark, Estonia, Sweden and the United Kingdom) users can access this information and monitor their e-health records more efficiently. Also, certain information should be available to users when using e-prescriptions. Denmark and Estonia recognised the importance to enable their users to monitor which medications were prescribed to them.

\section{Discussion}

The study showed that the development of e-services depends on 1) size of the state, 2) informatization of the state, and 3) information literacy of the citizens. We can determine that countries with a smaller population will have fewer problems with the implementation of e-services at the national level. Countries that appeared to be the most advanced in implementing these e-services were Denmark and Estonia. Both countries have an extremely high percentage of users of these e-services. In Estonia $47 \%$ of citizens and $95 \%$ of doctors use ehealth record and in Denmark almost $100 \%$ of doctors use it. When it comes to e-prescriptions, in Denmark almost $88 \%$ and in Estonia around $95 \%$ of users use the e-service. However, it is important to point out that both countries are relatively small (Denmark with around 5.6 million and Estonia with around 1.3 million citizens). On the other hand, a country like Germany with around 80 
million citizens and 16 constituent states will have much more difficulties with the implementation because of the complex state constitution. Also, countries with lower level of informatization or a greater disparity of informatization of rural and urban areas will have more problems introducing e-services. The complete transition from a traditional service to an e-service is possible only in case of complete informatization of health care which still presents a great challenge to certain countries that do not have sufficient financial resources and a clear strategy for the transition to a fully computerized system. Finally, in countries where information literacy is lower it is less likely that citizens will show willingness and interest in using such services. Denmark and Estonia are one of the most developed European countries by the ICT usage and development rankings, which is another reason for a high percentage of users.

\section{Conclusion}

There is no doubt that implementing e-services in health care leads to business optimization, but it is also important to point out all of the potential problems and disadvantages when implementing such large-scale and complicated services. When implementing e-services, it is necessary to make an assessment of the current situation and realistically assess the readiness of a country to implement e-health record and e-prescriptions at the national level. A prerequisite when introducing such services is making good foundations by improving the informatization level of the whole country. Also, it is important to be aware that in the first period after implementation not all of the benefits will be visible due to high costs of the development and implementation. Transparency in dealing with confidential data must be a priority so that citizens know what is happening with them at any time. When implementing e-services it is also important to implement technological solutions that will guarantee the security of the stored data. Policies and practices for long-term preservation of authentic and reliable data with preserved integrity and usability during the legally required period of time should be in place. However, it is also important to motivate citizens to use e-services in order to make the development and implementation financially worthwhile. When in doubt, users usually search for the answers online so it is important to make any information regarding the systems' operability available on the Internet. We suggest that e-services should, at minimum, provide information on the 52 questions set out in this research. By providing the basic or more detailed information, e-services will gain trust, users will be motivated to use them, and they will help improve the economy. 


\section{References}

Anderson, Ross J., (1996), A Security Privacy Model for Clinical Information Systems. IEEE Symposium on Security and Privacy. Oakland, California, pp. 30-43.

Barrows, C. Randolph and Clayton, D. Paul, (1996), Privacy, Confidentiality and Electronic Medical Records. Journal of the American Medical Informatics Association, Vol. 3, 2.

Cornford, Tony, Hibberd, Ralph; Barber, Nick (2014). The evaluation of the electronic prescription service in primary care. Final report, University of London, $158 \mathrm{pp}$.

Digitizing Public Services in Europe: Putting ambition into action. 9th Benchmark Measurement (2010), Directorate General for Information Society and Media, European Commission, http://ec.europa.eu/newsroom/dae/document.cfm?action=display\&doc_id=747, [25.01.2014]

E-government Gateway, (n.d.), Construction related documentation provision. https://www. epaslaugos.lt/portal/citizen/service/177, [01.07.2014]

EHMA, (n.d.), Report on the webinar "Introducing an e-National Patient Summary in Sweden: lessons from practice". http://www.ehma.org/files/Webinar\%20Public\%20Report;\%20 Introducing\%20an\%20e-National\%20Patient $\% 20$ Summary\%20in\%20Sweden.pdf, [12.07.2014]

ENTRUST, (2007), Understanding Digital Certificates \& Secure Sockets Layer. http://www.entrust.net/ssl-resources/pdf/understanding_ssl.pdf, [03.07.2014]

ePractice, (2014), eGovernment Factsheets Lithuania. http://www.epractice.eu/files/eGovernment \%20in\%20LT\%20-\%20May\%202014\%20-\%20v.16_0.pdf, [12.06.2014]

ePractice, (2014), eGovernment Factsheets United Kingdom. https://joinup.ec.europa.eu/sites/ default/files/98/c1/99/eGov\%20in\%20UK\%20May\%202014\%20v.16.0.pdf, [12.06.2014]

Ericsson Nikola Tesla d.d, (2005), Informacijski sustav primarne zdravstvene zaštite Republike Hrvatske. http://www.cezih.hr/pzz/dokumenti_pzz/HR_PHCIS_FunctionalSpecification.pdf, [16.07.2014]

Estonian e-Health Foundation, (2010), Overview of Estonian Electronic Health Record (EHR) System. http://www.e-tervis.ee/index.php/en/news-and-arcticles/432-overview-of-estonianelectronic-health-record-ehr-system, [07.05.2014]

Fleming, N. et al., (2011), The financial and nonfinancial costs of implementing electronic health records in primary care practices. PubMed, 30(3).

Gray, T. B., (2011), Electronic Health Records: An International Perspective on "Meaningful Use". http://www.commonwealthfund.org/ /media/Files/Publications/Issue\%20Brief/2011/ Nov/1565 Gray_electronic med records meaningful_use intl_brief.pdf, [30.06.2014]

HSCIC, (2013), A new way to get your medicines and appliances. http://systems.hscic.gov.uk/ eps/library/summary.pdf, [01.07.2014]

HSCIC, (n.d.), Electronic Prescription Service. http://systems.hscic.gov.uk/eps/library/ nhsecomms.pdf, [30.6.2014]

InterPARES Trust. http://interparestrust.org/, [07.01.2015]

J. Devlies, U. W., (2010), eHealth Strategies: Country Brief Belgium. http://ehealth-strategies.eu/ database/documents/Belgium_CountryBrief_eHStrategies.pdf, [16.07.2014]

Johansen, I., (2004), e-Prescriptions: ETP-Denmark. http://ehtel.eu/activities/tasks-sources/tfpatient-safety-emedication/ehtel-seminar-eprescribing-an-overview-of-challenges-andexperiences-in-europe-amsterdam-2004/files/dk_ib-johansen_2004.pdf, [23.05.2014]

Krag, B. H., (2012), eHealth in Denmark: eHealth as a part of a coherent Danish health care system. Danish Ministry of Health. http://www.sum.dk/ /media/Filer\%20-\%20Publikationer i_pdf/2012/Sundheds-IT/Sundheds_IT_juni_web.ashx, [17.07.2014]

Kushniruk, E. B., (2010), Advances in Electronic Helath Records in Denmark: From National Strategy to Effective Healthcare Sysetm Implementation. http://www.scopemed.org/ fulltextpdf.php?mno=2604, 「13.4.2014

Layne, K. and Lee, J., (2001), Developing fully functional E-government: A four stage model. Government Information Quarterly, 18 (2)

M. Püüa, U. V., (2012), Ten years of trusted Estonia. http://www.egov2012.gov.cy/mof/DITS/ conference/Europeone.nsf/All/E7916860932FBB22C2257ACB004BAEBE/\$file/s2SESSiON 2 No3 PUUA Vallner.pdf, [30.06.2014]

MedTech Europe, (n.d.), Denmark: Electronic patient records. http://www.reforminghealthcare. eu/economist-report/some-roads-ahead-innovative-approaches-in-five-west-europeancountries/denmark-electronic-patient-records, [17.07.2014] 
Menachemi, N. and Collum, T., (2011), Benefits and drawbacks of electronic health record systems

Murray, S. et al., (2004), Implementation strategies for e-government: A stakeholder analysis Approach

Oh, H., Rizo, C., Enkin, M., Jadad, A., (2005), What Is eHealth: A Systematic Review of Published Definitions, J Med Internet Res, 7 (1). http://www.jmir.org/2005/1/e1/, [15.02.2015]

Piccinelli, G., Stammers, E., (2001), From E-Processes to E-Networks: an E-Service-oriented approach. http://researcher.watson.ibm.com/researcher/files/us-bth/piccinelli.pdf, [15.11.2014]

Saluse et al., (2010), Assessing the Economic Impact/Net Benefits of the Estonian Electronic Health Record System. Tallinn

Schmitt, K. and Wofford, D., (2002), Financial analysis projects clear returns from electronic medical records. Healthc Financ Manage. PubMed, 56(1).

Smith, E. and Eloff, J. H. P., (1999), Security in health-care information systems -current trends. International Journal of Medical Informatics, Vol. 54, 1, pp. 39-54

Van Dijk, H. V., (2011), Electronic Prescribing in the United Kingdom and in the Netherlands. $\mathrm{http}$ //healthit.ahrq.gov/sites/default/files/docs/citation/europe-e-prescribing-report.pdf, [10.07.2014]

Van Langenhove, P. et al., (2013), eHealth European Interoperability Framework, European Commission

Zakon o arhivskom gradivu i arhivima (Official gazette/Narodne novine, 105/97) 